\title{
USE OF PRINCIPAL COMPONENTS ANALYSIS TO DESCRIBE THE SNAIL SHELL RESOURCE FOR HERMIT CRABS
}

\author{
ARMAND M. KurIs ${ }^{1}$ \\ Department of Zoology, University of Michigan, Ann Arbor, Michigan, U.S.A. \\ and \\ Michael S. BRoDY ${ }^{2}$ \\ Bodega Marine Laboratory, University of California, Bodega Bay, California, U.S.A.
}

\begin{abstract}
Principal components analysis of morphometric data from snail shells occupicd by hermit crabs enables the important dimensions of the shell to be described and quantified. A high correlation of the first principal component with crab size shows this component to be a better estimator of overall shell size than any of the original morphometric variates. Principal component II separated the shells utilized by adjacent populations of Coenobita and Calcinus according to shape.
\end{abstract}

\section{INTRODUCTION}

A hermit crab must occupy a snail shell or perish. Vance (1972a) has demonstrated experimentally that an increased availability of snail shells increased the density of a natural population of hermit crabs, confirming some previous suppositions (Haas, 1950; Provenzano, 1960; Reese, 1969; Hazlett, 1970a). Size and shape (snail taxa as modified by wear, encrustation and predator damage) are the two important parameters of snail shells as a resource for hermit crabs. Both are amenable to measurement. Shell size is an important determinant of the potential growth (Drapkin, 1963; Markham, 1968; Kuris \& Brody, unpubl.) and susceptibility to predation (Vance, 1972b) of the hermit crab occupant. Vance (1972a) used stepwise multiple regression to select the most highly correlated pair of variables among five shellsize and crab-size measurements. This procedure becomes increasingly unsatisfactory as species diversity of occupied shells increases and when many shells are in poor condition. Another potential difficulty in the choice of a single variable is that it is unlikely that the hermit crab is 'estimating' shell size in such a simplistic way; rather, the hermit crab presumably employs a Gestalt of the overall size-related suitability of the shell in question. A statistic describing overall size is needed.

When a principal components analysis (PCA) is made on a matrix of morphometric data drawn from a sample of related organisms, the first component (PC I) always seems to estimate size (see Blackith \& Reyment, 1971 for a technical discussion;

Present addresses: ${ }^{1}$ Department of Biological Sciences, University of California, Santa Barbara, California, U.S.A., and ${ }^{2}$ Department of Zoology, University of Texas, Austin, Texas, U.S.A. 
Colless, 1971 for a heuristic example). We show here that PC I (a size variable) is a better estimator of overall suitability of snail shells for hermit crabs than any single character. Furthermore, since PC I is uncorrelated with PC II, the latter permits quantification of factors largely unrelated to size of shell. PC II describes shell shape in a manner related to shell suitability. By means of PCA, resource quality may be compared within and between populations and species. The data described below demonstrate the power of PCA in an analysis of shell dimensions and resource suitability.

\section{Materials ANd Methods}

Two samples of hermit crabs and their shells, collected in August, 1972, at Punta Cacique, $2 \mathrm{~km}$ north of Playa del Coco, Guanacaste, Costa Rica are analysed. One sample included 69 Calcinus obscurus ${ }^{1}$ in 16 species of shells and 3 Clibanarius albidigitus in three species of shells all collected from a rocky intertidal habitat. The second sample of 63 Coenobita compressus in 21 species of shells, was collected from the contiguous supralittoral habitat over rocky, cobble, and sandy beach substrata. At low tide Coenobita often wanders in the upper intertidal zone but does not reach the region inhabited by the other species. We presume that all three crab species share a related resource pool because most of the shells utilized by Coenobita are from gastropods commonly found in the rocky intertidal zone inhabited by Calcinus and Clibanarius (see Appendix). Both samples were collected without regard to hermit crab and shell species or condition. An effort was made, however, to encompass the entire size-range of the occupied shells. No unoccupied shells were encountered on the surface of the substratum during sampling. Hermit crabs were identified from Holthuis (1954), snail shells with the aid of Keen (1971) ${ }^{1}$.

We used five measures of shell size, similar to those of Vance (1972a) Length was defined as the distance from tip of the spire to the anterior end of shell, measured along the anatomical axis of the shell. Width was the greatest distance at a right angles to length along the axis. In extremely globose species (e.g., Nerita spp.) width might exceed length. Aperture length was measured parallel to shell length - attenuate anterior siphons being excluded where they did not effectively contribute to the apertural opening available to hermit crabs. Aperture width was the greatest distance from the margin of the outer lip to the inner wall of the inner lip at $90^{\circ}$ to aperture length; parietal callosities were thus excluded from aperture width. Dry weight was the fifth variable. The volume of the shell interior is also of importance to hermit crabs, but volume estimates are difficult, time consuming, and often inaccurate and imprecise since up to $60 \%$ of the available shells were perforated or in some populations much of the spire was missing; volume determinations were not made. Five measurements of crab size were used, namely, total carapace length from the tip of the rostrum to

\footnotetext{
${ }^{1}$ See Appendix for taxonomic authorities.
} 
the posterior medial notch, hard carapace length from the tip of the rostrum to the cervical groove at the midline (i.e., shield length or anterior carapace), greatest length of the dactyl of the second left walking leg, greatest length of the major chela, and dry weight. All linear measurements were taken with vernier calipers to $0.1 \mathrm{~mm}$, all weights on an analytical balance to $0.001 \mathrm{~g}$. All variables were transformed to natural logarithms.

PCA begins by associating each shell with a point in a 5 dimensional space in which each dimension represents one of the $5 \log$-transformed shell variables. Any line through the origin in this space may be considered a new variable that gives to any shell a value equal to the distance from the origin to the perpendicular projection of that shell onto that line. The line that removes largest variance is the first principal component. Of the lines perpendicular to PC I, the one that accounts for the largest remaining variance is the second principal component, and so forth; all 5 components are uncorrelated. Eigenvectors provide a series of loadings which show the extent of the correlation of the original variables with the principal components. The shells are now plotted using PC I and PC II, the new axes (components), providing a simultaneous two dimensional view of the original five variables.

The common assumption in PCA is that the samples be drawn from a multivariate normal universe; consequently the variables will be continuous and linearly related to each other (Cassie, 1972). Seal (1964) also notes that PCA should not be used with data measured on different scales. Logarithmic transformation and normalization of the snail shell data matrix approximately satisfies these conditions. PCA is a relatively robust statistical approach (Blackith \& Reyment, 1971; Cassie, 1972), considered by many to be relatively insensitive to violations of normality and scaleinvariance although Seal (1964) and some others disagree. PCA has often been successfully employed with data of the present type. Multiple regressions were also performed on the logarithmic data. All calculations were carried out at the University of Michigan and University of Florida Computer Centers.

\section{RESULTS}

As expected, the covariance matrix of the combined samples showed that all five shell variables were highly correlated ( $n=135, r$ ranging from 0.665 to 0.841$)$. It is not, therefore, surprising that the eigenvector of PC I (Table I) yielded loadings (correlation coefficients) of the old shell characters with the new variable which were all high positive correlations of similar value. PC I accounted for $80.8 \%$ of the variance. In accord with other morphometric PCA studies PC I is most reasonably interpreted as a synthetic variable representing overall size. A similar analysis of the five crab characters showed that PC I also represented size and removed $95.6 \%$ of the variance. Since only three crab species were involved (compared with 28 shell species) and four of the five measured variables are of similar relative proportions in all three species, PC I includes virtually all of the variance. The close relationship 
TABLE I

Correlation of original snail shell variables with principal components: eigenvalues are given as percentages of the total variance accounted for by each principal component.

\begin{tabular}{lrrrrr}
\hline Original variables & \multicolumn{5}{c}{ Principal components } \\
\cline { 2 - 6 } & \multicolumn{1}{c}{ I } & II & III & IV & V \\
\hline Shell length & & & & & \\
Shell width & 0.444 & 0.539 & -0.042 & 0.548 & -0.459 \\
Aperture length & 0.458 & -0.393 & 0.190 & -0.479 & -0.608 \\
Aperture width & 0.448 & 0.244 & -0.695 & -0.415 & 0.289 \\
Shell weight & 0.430 & -0.657 & -0.148 & 0.528 & 0.287 \\
Eigenvalues & 0.455 & 0.251 & 0.676 & -0.142 & 0.504 \\
\hline
\end{tabular}

between crab size and shell size for the two common species is apparent (Fig. 1). Log total carapace length is used rather than crab PC I for reasons given below. Regression equations for the shell size-crab size relationship are of the semilogarithmic form, In $\hat{Y}=\ln a+b X$. For Calcinus $a=4.91, b=0.199$; for Coenobita $a=7.72, b=$ 0.223 . Coenobita is using relatively small shells compared with the marine species. The higher slope for Coenobita also suggests that large individuals occupy progressivcly poorcr shells.

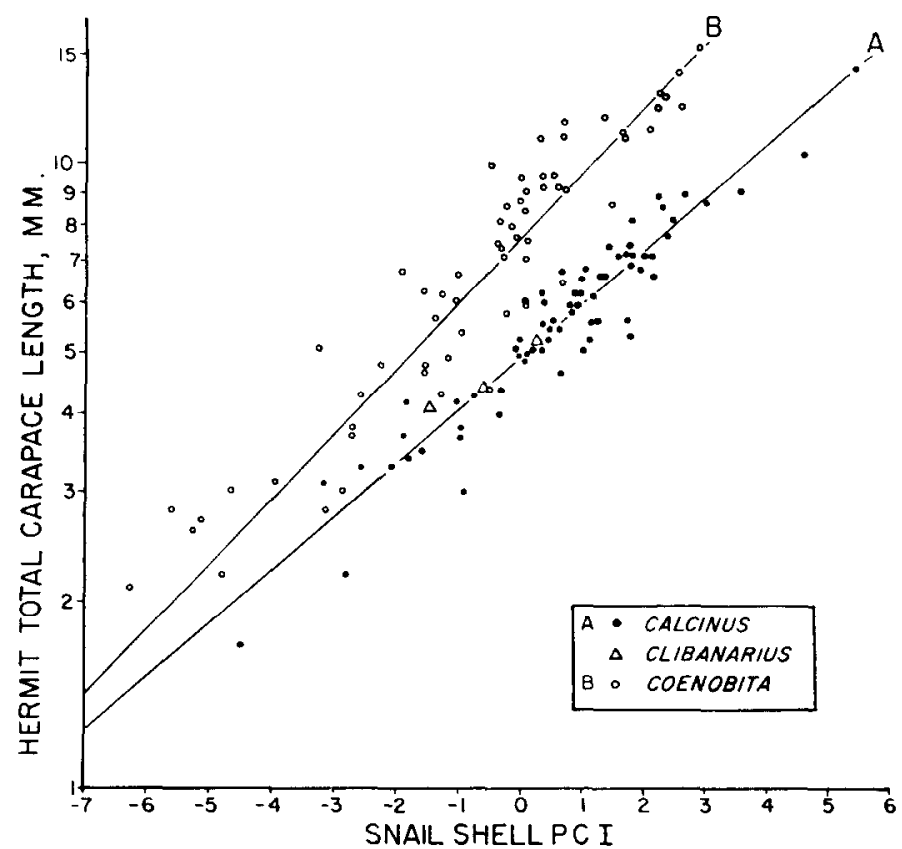

Fig. 1. Relationship between snail shell size, described by principal component $I$ and crab size estimated by log total carapace length for the land hermit crab, Coenobita and an adjacent population of the marine hermit crabs, Calcinus and Clibanarius. 


\section{DISCUSSION}

Is PC I a more reliable estimator of shell size for hermit crabs than selection by multiple regression of the best pair of shell and crab size correlates? Table II ranks the shell size-hermit crab size regression models by $R^{2}$. Multiple regression of the five crab characters on the five shell characters showed crab weight and aperture width to be most highly correlated for the field sample of Calcinus and total carapace length and aperture width for Coenobita. Crab weight and shell width were the most closely correlated variates of three species of Pagurus in the outcome of preference experiments (Vance, 1972a) involving only 11 species of available shells. Re-calculation of the multiple regression analysis for Calcinus and Coenobita now including PC I of

\section{TABLE II}

Ranking of hermit crab size-snail shell size regression models by $R^{2}$ : comparison of Principal component I (PC I) as a size estimator with most highly correlated crab and shell measurements (all data. logarithmic): $N=$ sample size, $y=$ dependent variable, $x=$ independent variable, $R^{2}=$ multiple correlation coefficient).

\begin{tabular}{|c|c|c|c|}
\hline $\begin{array}{l}\text { Hermit } \\
\text { species }\end{array}$ & $\begin{array}{c}y \\
\text { Crab size variable }\end{array}$ & $\begin{array}{c}x \\
\text { Shell size variable }\end{array}$ & $R^{2}$ \\
\hline \multicolumn{4}{|c|}{ Calcinus obscurus $(N=68)$} \\
\hline & Weight & PC I & 0.913 \\
\hline & PC I & PC I & 0.904 \\
\hline & Total carapace length & PC I & 0.890 \\
\hline & Weight & Aperture width ${ }^{1}$ & 0.769 \\
\hline \multicolumn{4}{|c|}{ Coenobita compressus $(N=63)$} \\
\hline & Total carapace length & PC I & 0.890 \\
\hline & PC I & PC I & 0.871 \\
\hline & Total carapace length & Aperture width ${ }^{1}$ & 0.861 \\
\hline & Weight & PC I & 0.788 \\
\hline \multicolumn{4}{|c|}{ Pagurus beringanus $(N=64)^{2}$} \\
\hline & Weight & Shell width & 0.945 \\
\hline \multicolumn{4}{|c|}{ P. granosimanus $(N=100)^{2}$} \\
\hline & Weight & Shell width & 0.940 \\
\hline \multicolumn{4}{|c|}{$P$. hirsutiusculus $(N=105)^{2}$} \\
\hline & Weight & Shell width & 0.837 \\
\hline
\end{tabular}

\footnotetext{
' Best pair of crab and shell size measurements based on stepwise multiple regression.

${ }^{2}$ Best pair of crab and shell size measurements based on shell selection experiment (from Vance 1972a).
}

both crabs and shells showed that the highest correlation is between the best original crab size variable and the shell size estimator, PC I. The use of shell PC I improves the correlation dramatically for Calcinus and somewhat for Coenobita. Correlations for field samples of both species are now within the range of Vance's (1972a) preference experiments. PC I for the crab data was not an improvement over the best original variable (although PC I was better than the remaining four variables). In a very highly correlated matrix, allometric growth, missing appendages, and sexual dimor- 
phism increase variance, and thus reduce the efficacy of $\mathrm{PCI}$ as a size estimator. Certain$\mathrm{ly}$, the labour involved in taking four additional measurements does not justify the use of PC I as a crab size estimator. Indeed, we chose total carapace length as our estimator of crab size for both species because it gave the best correlation with shell size (PC I) for Coenobita and a close third best (after crab weight and PC I) for Calcinus and it is certainly a less time-consuming measurement than crab weight.

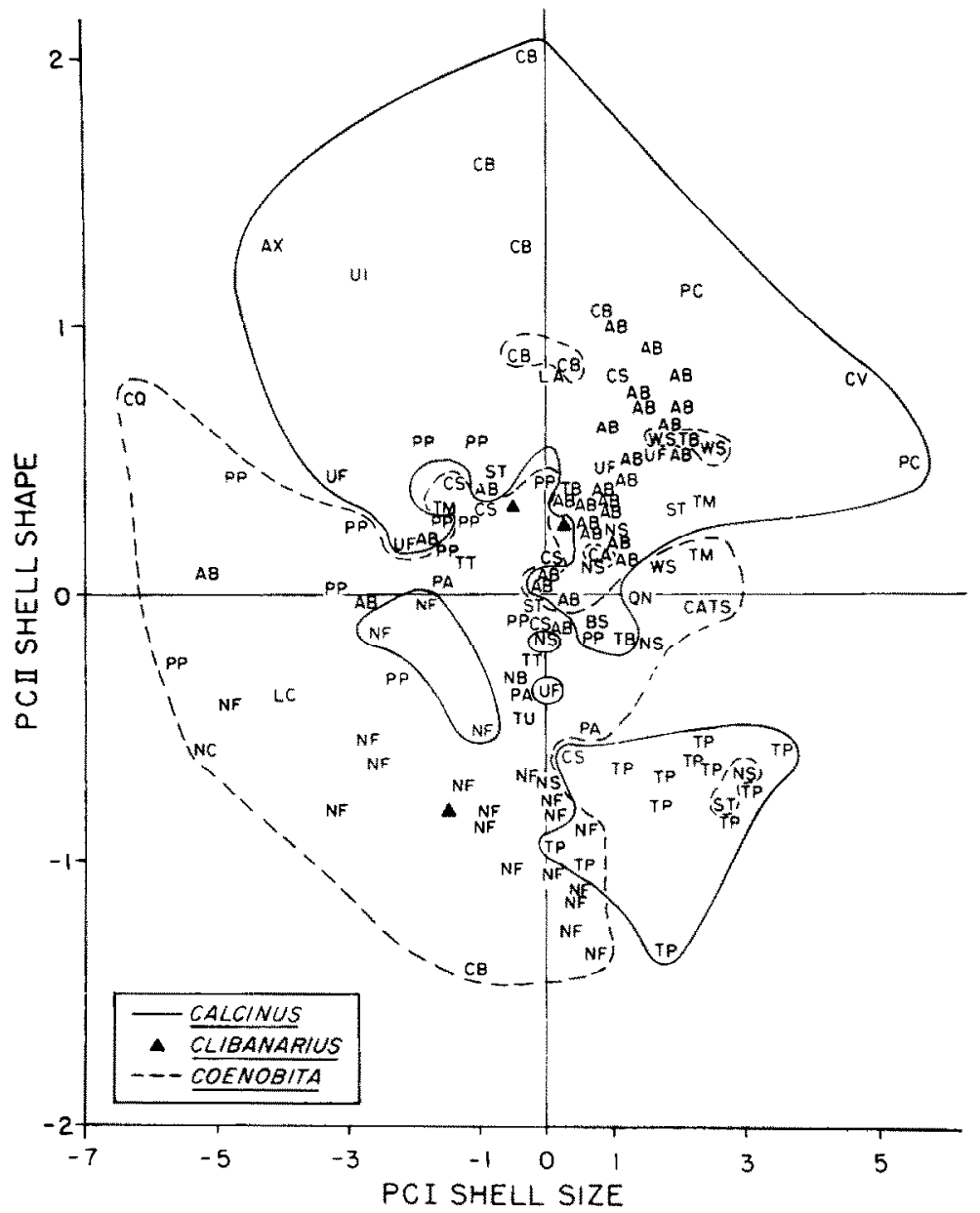

Fig. 2. New data for snail shells on first two principal components: shells occupied by Calcinus enclosed by solid line, Coenobita by broken line, Clibanarius by triangles: see Appendix for key.

The use of PCA to estimate shell size is a technique that will yield a high correlation with crab size even in field samples having a high diversity of shell species. Samples from very different localities having scant overlap of shell species may be combined in PCA. 
Another important advantage of PCA is that PC I incorporates the variance due to size. After eliminating the variance due to size, that due to shape may now be isolated and investigated. PC II (Table I) accounts for $8.6 \%$ of the variance and shows a strong positive correlation with shell length and a lower correlation with aperture length and weight. Aperture width and, somewhat less so, shell width are negatively correlated with PC II. In visual terms, those shells having a high score on the second component (Fig. 2) tend to he high spired (Cantharus, Planaxis), heavy (Columbella, Acanthina) and relatively sculptured (Cymatium, Cantharus, Latirus). Sculpture (ribs, varices, spines) adds weight without greatly affecting the linear dimensions. Low PC II scores were attained by globose (naticids, Nerita), trochoid (Tegula) and relatively light shells (Nerita resorbs the inner walls of the old whorls as it grows). By stressing differences between length and weight on one hand and width (especially aperture width), PC II is seen to provide information on an unmeasured character, shell volume, which may be of importance to hermit crabs (Hazlett, 1970b). Shells with a high PC II value have a relatively small interior space.

The species of snail shells occupied by Coenobita and Calcinus overlap considerably at Punta Cacique (see Appendix). Unexpectedly, PC II showed that the assemblage of shells used by Calcinus differed markedly in shape from those used by Coenobita. With the major exception of Tegula, shells occupied by Calcinus had high PC II values, while Coenobita shells had low scores (Fig. 2). This difference is not just due to the differential availability of shell species since in most cases in which both crab species used the same shell species (Nerita spp., Acanthina, Planaxis, Columbella, but not Cantharus) conspecific shells born by Calcinus had higher PC II values. Mann-Whitney 1-tailed U-tests (Sokal \& Rohlf, 1969) were significant for all but Planaxis $(0.10>\mathrm{P}>0.05)$. Re-examination of shells occupied by Coenobita demonstrated that the land hermit crab tends to remove the columella and inner walls and to reduce the inner face of the outer wall by abrasion.

PC III, which accounts for only $5 \%$ of the variance, does not further define the shell as a resource.

PC I and PC II quantify aspects of the shell resource which determine their suitability for hermit crabs. Adequacy of the shell, as described through regression analysis, is reflected in terms of fitness attributes such as growth rate, size at maturity, fecundity and susceptibility to predation.

\section{ACKNOWLEDGEMENTS}

Dr G. Estabrook greatly helped in our decision to use principal components analysis as a multivariate technique and further advised in computer analysis, and Dr J. Rosewater of the United States National Museum graciously identified difficult specimens.

This study was partially funded by an NIH postdoctoral fellowship to A.M.K. 


\section{REFERENCES}

Blackith, R. E. \& R. A. Reyment, 1971. Multivariule morphometrics. Academic Press, New York, 412 pp.

Cassie, R. M., 1972. A computer programme for multivariate statistical analysis of ecological data. J. exp. mar. Biol. Ecol., Vol. 10, pp. 207-241.

Colless, D. H., 1971. An application of numerical methods to the systematics of microfilariae. Ann. trop. Med. Parasit., Vol. 65, pp. 245-251.

Drapkin, E. I., 1963. Effect of Rapana bezear Linné (Mollusca, Muricidae) on the Black Sea fauna. Dokl. Akad. Nauk S.S.S.R., Vol. 151, pp. 700-703.

HaAs, F., 1950. Hermit crabs in fossil snail shells in Bermuda. Ecology, Vol. 31, p. 152.

HAzLetT, B. A., 1970a. Interspecific shell fighting in three sympatric species of hermit crabs in Hawaii. Pacif. Sci., Vol. 24, pp. 472-482.

Hazlett, B. A., 1970b. Tactile stimuli in the social behavior of Pagurus bernhardus (Decapoda, Paguridae). Behaviour, Vol. 36, pp. 20-48.

Holthius, L. B., 1954. On a collection of decapod Crustacea from the Republic of El Salvador (Central America). Zool. Verh., Leiden, Bd. 23, S. 1-43.

Keen, A. M., 1971. Sea shells of tropical west America. Stanford University Press, Stanford, California, $1064 \mathrm{pp}$.

Markham, J. C., 1968. Notes on growth-patterns and shell-utilization of the hermit crab Pagurus bernhardus (L.). Ophelia, Vol. 5, pp. 189-205.

Provenzano, A. J., 1960. Notes on Bermuda hermit crabs (Crustacea: Anomura). Bull. mar. Sci. Gulf Caribb., Vol. 10, pp. 117-124.

REESE, E. S., 1969. Behavioral adaptations of intertidal hermit crabs. Am. Zool., Vol. 9, pp. 343-355

SE AL, H. 1964. Multivariate statistical analysis for biologists. Methuen, London, $207 \mathrm{pp}$.

So kal, R. R. \& F. J. RollL,, 1969. Biometry. W. H. Freeman, San Francisco, 776 pp.

VANCE, R. R., 1972a. Competition and mechanism of coexistence in three sympatric species of intertidal hermit crabs. Ecology, Vol. 53, pp. 1062-1074.

$V_{A N C E}, R$. R., 1972b. The role of shell adequacy in behavioral interactions involving hermit crabs. Ecology, Vol. 53, pp. 1075-1083. 


\section{APPENDIX}

Frequency of snail shells occupied by hermit crabs at Punta Cacique, Costa Rica: taxonomic authorities according to Holthuis (1954) and Keen (1971).

\begin{tabular}{|c|c|c|c|c|c|}
\hline \multirow[b]{2}{*}{ Family } & \multirow[b]{2}{*}{ Species } & \multirow[b]{2}{*}{ Code } & \multicolumn{3}{|c|}{ Number occupied by } \\
\hline & & & 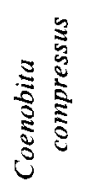 & 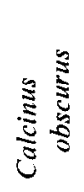 & 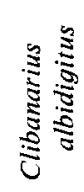 \\
\hline Trochidae & Tegula pellisserpentis (Wood) & $\mathrm{TP}$ & & 12 & \\
\hline Turbinidae & Turbo squamiger Reeve & TU & 1 & & \\
\hline \multirow[t]{2}{*}{ Neritidae } & Nerita funiculata Menke & NF & 18 & 3 & 1 \\
\hline & N. scabricosta Lamarck & NA & 3 & 3 & \\
\hline \multirow[t]{2}{*}{ Littorinidae } & Littorina angiostoma Adams & $\mathrm{NC}$ & 1 & & \\
\hline & L. modesta Philippi & $\mathrm{LC}$ & 1 & & \\
\hline \multirow[t]{2}{*}{ Cerithiidae } & Cerithium adustum Kiener & QN & 1 & & \\
\hline & C. stercusmuscarum Valenciennes & WS & 3 & & \\
\hline Planaxidae & Planaxis planicostatus Sowerby & PP & 9 & 4 & 1 \\
\hline \multirow{2}{*}{ Naticidae } & Natica broderipiana Récluz & NB & 1 & & \\
\hline & Polinices uber (Valenciennes) & PA & 3 & & \\
\hline Cymatiidae & Cymatium vestitum (Hinds) & $\mathrm{CV}$ & & 1 & \\
\hline Bursidac & Bursa caelata (Broderip) & $\mathrm{CA}$ & 2 & & \\
\hline \multirow[t]{6}{*}{ Thaididae } & Acanthina brevidentata (Wood) & $\mathrm{AB}$ & 3 & 25 & 1 \\
\hline & Thais biserialis (Blainville) & ТВ & 1 & 3 & \\
\hline & $T$. melones (Duclos) & TM & 2 & 1 & \\
\hline & T. speciosa (Valenciennes) & TS & 1 & & \\
\hline & T. triangularis (Blainville) & TT & 2 & & \\
\hline & Purpura columellaris (Lamarck) & PC & & 2 & \\
\hline \multirow[t]{2}{*}{ Buccinidae } & Cantharus elegans (Griffith and Pidgeon) & $U F$ & & 4 & \\
\hline & C. sanguinolentus (Duclos) & $\mathrm{CS}$ & 4 & 2 & \\
\hline \multirow[t]{2}{*}{ Columbellidae } & Anachis sp. & $\mathrm{AX}$ & & 1 & \\
\hline & Columbella strombiformis Lamarck & $\mathrm{CB}$ & 3 & 4 & \\
\hline Nassariidae & Nassarius sp. & VI & & 1 & \\
\hline \multirow[t]{3}{*}{ Fasciolariidae } & Latirus sp. & $\mathrm{CQ}$ & 1 & & \\
\hline & Leucozonia cerata (Wood) & $\mathbf{L A}$ & & 1 & \\
\hline & Opeatostoma pseudodon (Burrow) & ST & 2 & 2 & \\
\hline \multirow[t]{2}{*}{ Bullidae } & Bulla punctulata Pilsbry & BS & 1 & & \\
\hline & & & 63 & 69 & 3 \\
\hline
\end{tabular}

